\title{
Os modelos cosmológicos geocêntrico e heliocêntrico da Terra como tema motivador para alunos do CEEFJA-Marabá/PA de acordo com o Ciclo de Aprendizagem Kellyana
}

The Earth's geocentric and heliocentric cosmological models as a motivating theme for CEEFJAMarabá/PA students according to the Kellyana Learning Cycle

\author{
A. A. Martins Neto*, N. N. Soares \\ Mestrado Profissional em Ensino de Fisica/ICE - Instituto de Ciências Exatas, UNIFESSPA, 68507-590, marabá-PA \\ *augustoneto@unifesspa.edu.br
}

(Recebido em 26 de fevereiro de 2019; aceito em 07 de maio de 2019)

\begin{abstract}
O presente trabalho descreve como os modelos cosmológicos da Terra, geocêntrico e heliocêntrico, podem ser utilizados como ferramenta motivadora no processo ensino-aprendizagem na Educação Fundamental de Jovens e Adultos. Para a realização do trabalho foi aplicado um questionário para quinze estudantes da Escola Jonathas Pontes Athias no Centro de Educação de Ensino Fundamental de Jovens e Adultos (CEEFJA) em Marabá e utilizados como referencial teórico os Corolários da Teoria dos Construtos Pessoais de George Kelly, através do Ciclo de Experiência Kellyana (CEK) que descrevem as experiências do indivíduo. O questionário foi aplicado antes e depois de uma aula sobre cosmologia utilizando recursos didáticopedagógico que envolviam meios tecnológicos e uma abordagem histórica. Após a aula, foi observado respostas mais precisas sobre o assunto ministrado.

Palavras-chave: Modelos Cosmológicos da Terra, Construtos Pessoais Kellyano, Ensino-aprendizagem.
\end{abstract}

The present work describes how the Earth's cosmological models: geocentric and heliocentric can be used as a motivating tool in the teaching-learning process in the Fundamental Education of Young and Adults. A questionnaire was administered to fifteen students of the Jonathas Pontes Athias School at the Youth and Adult Elementary Education Center (CEEFJA) in Marabá and used as a theoretical reference the Coronaries of the Personal Builders Theory of Kelly through the Experience Cycle Kellyana (CEK) who describe as individual experiences. The chart was constructed before and after a lecture on applied cosmology didacticpedagogical resources involving technological means and a historical approach. After a class, more precise answers on the subject were given.

Keywords: Cosmological Models of the Earth, Personal Constructions Kellyano, Teaching-learning.

\section{INTRODUÇÃO}

O estudo da Cosmologia em aulas de Ciências no Ensino Fundamental faz parte do eixo "Terra e Universo" nos Parâmetros Curriculares Nacionais[10] devendo, desta forma, ser trabalhada com maior ênfase em sala de aula, no entanto, quando se desenvolve alguma atividade voltada para esta temática, deixa muitos alunos e professores frustrados. São diversos os motivos desta frustração, os quais destacamos: pouco interesse do aluno (em particular da Educação de Jovens e Adultos) em conhecer sobre a origem do Universo, e consequentemente de saber qual o lugar de importância que ele (aluno/ser) ocupa em função do equilíbrio do Cosmo; falta de conhecimento do Professor, pois, em geral, os professores do Ensino Fundamental não são graduados em Física, com isto o ensino tende a ser ministrado, em geral, por meio de aulas teóricas e superficiais, com pouca motivação e desinteressante para o aluno; considerando-se ainda a falta de recursos manipuláveis/tecnológicos de observação e registro, que poderiam provocar nos alunos um sentimento de pesquisador. Assim, para ensinar sobre modelos cosmológicos, além da teoria, é necessário que o professor use recursos visuais e/ou experimentais para observar com maior clareza os fenômenos e fazer o aluno criar sua própria base científica.

Diversos trabalhos de pesquisa em ensino indicam que os estudantes desenvolvem melhor sua aprendizagem sobre Ciências e aprimoram melhor suas apreensões conceituais quando se colocam 
(ou são colocados) em situações de investigações científicas, semelhantes às feitas em laboratórios de pesquisa [2].

Isto mostra a importância do docente em diversificar a aula com vídeos, animações e experiências práticas. E devido a Cosmologia trazer em seu campo de estudo conteúdos intrigantes, pode despertar grande interesse do aluno pela compreensão do Universo, em particular, de como nosso Sistema Solar se comporta nele.

Com a finalidade de tornar o processo de ensino e aprendizagem mais dinâmico, o professor pode se utilizar de recursos motivadores que façam com que os alunos sintam vontade de aprender, aguçando neles a curiosidade, bem como despertar a criatividade, tão essencial na formação de futuros cientistas e pesquisadores. O conteúdo por sua vez precisa ter significado, fazer sentido, e estar relacionado com o cotidiano do aluno, para que assim ocorra a aprendizagem.

\section{OBJETIVO}

Este trabalho tem como objetivo aplicar três Corolários da Teoria dos Construtos Pessoais de Kelly, com fins de provocar motivação dos alunos, através de uma aula diferenciada sobre modelos cosmológicos Geocêntricos e Heliocêntricos da Terra com a utilização de recursos audiovisuais e uma experiência prática de baixo custo para a construção e experimentação de um relógio solar.

\section{REFERENCIAL TEÓRICO}

Na Teoria de Kelly sobre os construtos pessoais, o homem é visto como "cientista", pois busca prever e controlar eventos. Deste modo, em sua teoria um "construto" é uma representação, uma ideia, percebida diferentemente por cada indivíduo, dada por observações em suas experiências de vida, em um curso de eventos, gerando inferências. O teste de um construto é um teste frente a eventos subsequentes [1], ou seja, pode gerar novas representações.

Assim, um construto (ideia) quando testado sua validade, pode ser negativo ou positivo. Se for negativo, ou seja, se a ideia estiver "errada", uma nova deve ser criada até se obter um resultado positivo, mas não definitivo, pois, a pessoa pode recursivamente melhorar a construção de suas ideias, aumentando o repertório de seus construtos, ou subordinar estes a construtos superordenados, isto é, por novas proposições ou proposições mais abrangentes.

Nesta perspectiva, a aprendizagem segundo a Teoria de Kelly, se dá de modo que o aluno seja construtor do seu conhecimento e é resultado das experiências que o mesmo vivencia na escola, sendo passível de mudança por sucessivas repetições, conforme Moreira (1999) [1].

George Kelly em sua teoria possui 11 corolários, porém iremos apresentar somente três que estão relacionados com as ações de ensino desenvolvidas e apresentadas neste trabalho.

\subsection{Corolário da Individualidade}

Segundo o corolário da individualidade, as pessoas possuem uma percepção singular do mundo ao seu redor, neste sentido, cada pessoa é um pesquisador ao seu modo. Na Teoria de Kelly o corolário da individualidade diz que as pessoas diferem não só porque pode haver diferenças nos eventos que tentam antecipar, mas também porque há diferentes abordagens à antecipação dos mesmos eventos [1]. Desta forma, infere-se que o estudante formula as suas próprias ideias, que podem ser trocadas, ou compartilhadas em sala de aula para construção de um novo conhecimento. Já o corolário da construção diz que "uma pessoa antecipa eventos construindo suas réplicas" (p. 129) [1]. Com este corolário Kelly quer evidenciar que os indivíduos colocam uma interpretação naquilo que constrói. Os estudantes vão construindo seu conhecimento à medida que vai assimilando o conteúdo da aula ministrada e fazendo réplicas do experimento pelas observações. Neste corolário, "O sistema de construção de uma pessoa varia à medida que ela constrói, réplicas de eventos" (p. 133) [1]. No caso do estudante, ele vai construindo seu conhecimento pelas várias formas de observar um determinado fenômeno, e a cada observação feita, ele pode fazer uma interpretação diferente, uma réplica diferente, até chegar a melhor conclusão possível para ele. $\mathrm{Na}$ Teoria de Kelly, o processo de aprendizagem é focado em cinco momentos: antecipação, investimento, encontro, confirmação e revisão. O Ciclo da Experiência Kellyana (CEK) começa na 
etapa da antecipação, momento em que a pessoa utiliza os construtos que já concebeu, dado pelo processo de construção de seus modelos, ou representações e busca antecipar um evento que pode vir a acontecer [9]. Após esta fase, o indivíduo inicia o envolvimento com a etapa do investimento. Neste momento, é possível acontecer uma melhora da representação, com a introdução de novos saberes, dando maior clareza ao evento que está por acontecer. Na passagem por essa segunda etapa, o indivíduo é preparado para a etapa do encontro. Em seguida, avalia suas teorias pessoais, e neste momento denominado etapa da confirmação ou desconfirmação, ele confirma ou não suas hipóteses através da vivência no evento. Para finalizar o CEK, o indivíduo é levado a reconstruir seus construtos, etapa essa chamada de revisão construtiva [9].

Para testar o CEK, foi desenvolvida uma sequência didática, que será abordada mais adiante, onde o aluno passa por cada uma das etapas do ciclo, com a aplicação primeiramente de um questionário, antecipando o evento. Em seguida, na etapa do investimento, terá participado de aula expositiva, auxiliada com aplicação de vídeo documentário. No encontro, é proposto o experimento relógio de sol, onde o estudante se depara com o evento que antecipou, seguida da etapa de confirmação, ou não das hipóteses (respostas dadas no questionário) e, finalmente, a revisão, com a aplicação de um questionário final, para possíveis reconstrução de seu construto inicial.

\subsection{Corolário da Construção}

Já o corolário da construção nos diz que "uma pessoa antecipa eventos construindo suas réplicas" (p. 129) [1]. Com este corolário Kelly quer evidenciar que a pessoa coloca uma interpretação naquilo que construiu. $\mathrm{O}$ aluno vai construindo seu conhecimento à medida que vai assimilando o conteúdo da aula ministrada e fazendo réplicas do experimento pelas observações, por exemplo, até conseguir a visualização correta do experimento.

\subsection{Corolário da Experiência}

Neste corolário, "O sistema de construção de uma pessoa varia à medida que ela constrói, sucessivamente, réplicas de eventos" (p. 133) [1]. No caso do aluno, ele vai construindo seu conhecimento pelas várias formas de observar um determinado fenômeno, e a cada observação feita, ele pode fazer uma interpretação diferente, uma réplica diferente, até chegar a melhor conclusão possível para ele.

\subsection{O Ciclo de Experiência Kellyana (CEK)}

Na Teoria de Kelly, o processo de aprendizagem é focado em cinco momentos: antecipação, investimento, encontro, confirmação e revisão.

O Ciclo da experiência Kellyana (CEK) começa na etapa da Antecipação, momento em que a pessoa utiliza os construtos que já concebeu, dado pelo processo de construção de seus modelos, ou representações e busca antecipar um evento que pode vir a acontecer [9].

Após esta etapa, a pessoa inicia o envolvimento com a etapa do Investimento, isto é, quando ela se prepara para se encontrar com o evento. Neste momento, é possível acontecer uma melhora da representação, com a introdução de novos saberes, dando maior clareza ao evento que está por acontecer. Na passagem por essa segunda etapa, a pessoa é preparada para a etapa do Encontro o qual é caracterizada pelo momento específico no qual vai se deparar com o evento que antecipou. Em seguida, a pessoa avalia suas teorias pessoais, e neste momento denominado Etapa da confirmação ou desconfirmação, ela confirma ou não suas hipóteses através da vivência no evento. Para finalizar o CEK, a pessoa é levada a reconstruir seus construtos, etapa essa chamada de Revisão Construtiva [9].

\subsection{Modelos Cosmológicos Geocêntrico e Heliocêntrico da Terra}

A teoria do universo geocêntrico, baseada na hipótese de que a Terra está parada no centro do Universo com os demais corpos celestes, incluindo o Sol, girando ao seu redor, é o modelo cosmológico mais antigo conhecido. Na Antiguidade esta era a visão mais aceita entre os Filósofos, 
dentre os quais, o mais conhecido era Aristóteles (384-322 a.C.). No entanto, foi o grego Claudius Ptolomeu (78-161 d.C.), matemático e astrônomo, quem apresentou a forma, como é conhecido hoje esta teoria. Esse modo de conceber o universo foi predominante no pensamento humano até a aceitação da Teoria heliocêntrica, de que o Sol está no centro do sistema solar e que os planetas giram em torno dele, criada pelo astrônomo grego Aristarco de Samos (310-230 a.C.), e resgatada pelo astrônomo e matemático polonês Nicolau Copérnico (1473-1543). Para Copérnico, as órbitas dos planetas são circunferências e o Sol está no centro, em oposição ao modelo Geocêntrico (Figura $1)$.

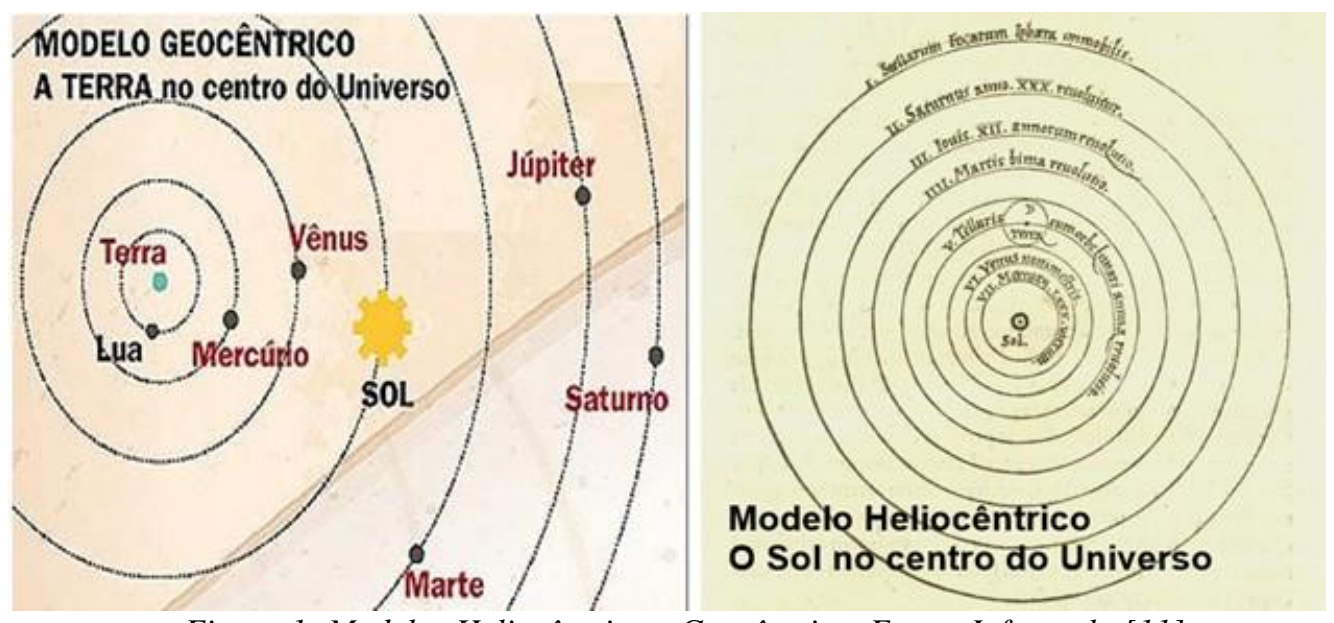

Figura 1: Modelos Heliocêntrico e Geocêntrico. Fonte: Infoescola [11].

O modelo concebido por Copérnico foi reestruturado e aprimorado por Johannes Kepler (15711630 d.C.). No entanto, a explicação física para o modelo de Kepler foi estabelecida por Isaac Newton (1643-1727 d.C.) ao formular a lei da gravitação universal, que é válida até hoje. No século XVII, Kepler apresentou as três leis que regem o movimento planetário, utilizando anotações do astrônomo Tycho Brahe (1546-1601).

Primeira Lei de Kepler: Também conhecida como "Lei das Órbitas", Kepler propôs um modelo elíptico em detrimento do modelo da circunferência, confirmando que os planetas descrevem órbitas elípticas em torno do Sol ao invés da forma circular (Figura 2).

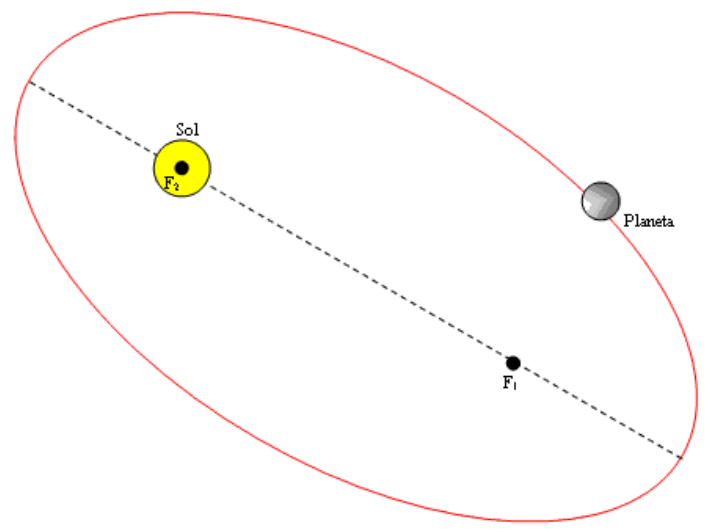

Figura 2: Movimento orbital dos planetas. Fonte: Só Física [12].

Segunda Lei de Kepler: Chamada de "Lei das Áreas", a segunda lei de Kepler assegura que os segmentos (raio vetor) que unem o sol aos planetas correspondem a áreas $\left(\mathrm{A}_{1} \mathrm{e} \mathrm{A}_{2}\right)$ iguais em intervalos de tempo $(\Delta t)$ iguais, como exemplificado na Figura 3. A partir disso, dependendo da distância que um planeta dista do sol, a velocidade do movimento será diferente. 


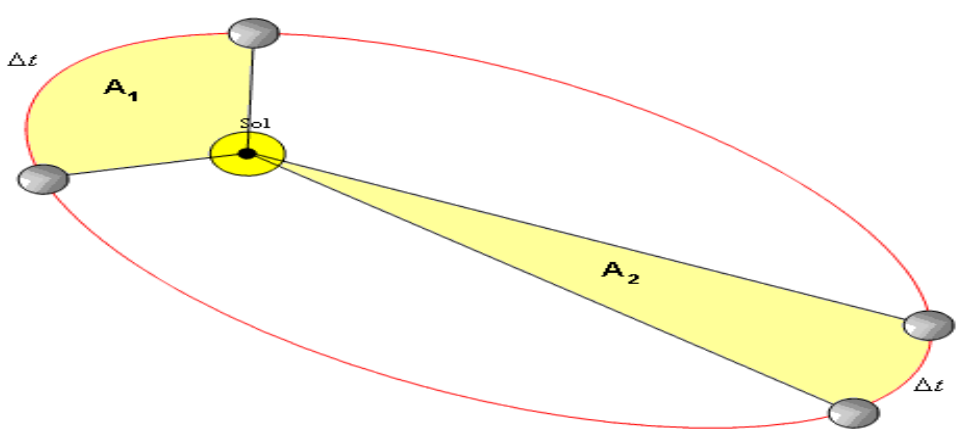

Figura 3: Lei das áreas. Fonte: Só Física [12].

$$
\frac{A_{1}}{\Delta t}=\frac{A_{2}}{\Delta t}
$$

Terceira Lei de Kepler: Também conhecida como "Lei dos Períodos", a terceira lei de Kepler aponta a existência da relação entre a distância de cada planeta e seu período de Translação (movimento que descreve a volta em torno do sol correspondente ao período dos anos). Por isso, quanto mais afastado estiver o planeta do sol, mais tempo levará para completar o movimento de translação. O enunciado desta lei é o seguinte: Para qualquer planeta do Sistema Solar, é constante a razão entre o quadrado do período orbital $\left(T^{2}\right)$ do planeta e o cubo do semieixo maior $\left(R^{3}\right)$ de sua órbita em torno do Sol.

A terceira Lei de Kepler é descrita da seguinte maneira:

$$
K=\frac{T^{2}}{R^{3}}
$$

onde, o parâmetro $\mathrm{T}$ é o período de translação dos planetas, $\mathrm{R}$ é o raio médio das órbitas dos planetas e K é uma constante de proporcionalidade que depende da massa do Sol.

\section{MATERIAL E MÉTODOS}

Este trabalho tem abordagem qualitativa, pois uma pesquisa qualitativa se preocupa com a compreensão das características de um grupo social, de uma organização, de um fenômeno, levando em consideração inclusive dados numéricos passíveis de interpretações [9].

Neste sentido, desenvolvemos neste trabalho que apresenta ainda, por meio de uma das atividades um caráter metodológico experimental, uma pesquisa com questões subjetivas para melhor compreensão de análise acerca dos resultados.

A pesquisa foi realizada em uma turma do Centro de Educação de Jovens e Adultos na escola Jonathas Pontes Athias, com 15 alunos na disciplina de Ciências Naturais. No total, o computo das aulas realizadas com apoio de uma Sequência Didática teve duração de 3 horas, envolvendo o questionário inicial, a aula expositiva, o vídeo no primeiro momento e a aula prática e o questionário final no segundo momento. Os participantes foram informados sobre o objetivo da pesquisa e assinaram o Termo de Consentimento Livre e Esclarecido (TCLE). O foco era a discussão com os alunos acerca da Cosmologia, sua importância e fundamentação, e construção e experimentação de um relógio de sol, fazendo os alunos participarem efetivamente na construção de seus conhecimentos. A seguir, apresenta-se a sequência didática seguida pelo professor em acordo com a Teoria dos Construtos pessoais de Kelly (Figura 4). 


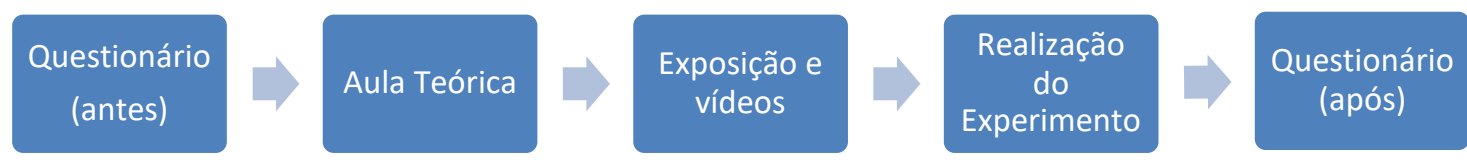

Figura 4: Esquema da Sequência Didática.

\subsection{Etapas da Pesquisa}

4.1.1 Aplicação do Questionário de sondagem.

Esta atividade foi realizada com as seguintes perguntas:

\section{O que é o Universo?}

2. Você sabe o que é Cosmologia?

3. Porque existe o dia e a noite?

4. Onde está o Sol durante a noite?

A partir destes questionamentos, que tinham o intuito de possibilitar aos alunos a pensarem no que seria trabalhado durante a aula, buscou-se estimular a curiosidade dos alunos. Assim, as perguntas foram aplicadas para saber o que os alunos entendiam sobre cosmologia e o porquê de determinados fenômenos. Após a aplicação do questionário, criaram-se categorias de classificação para posterior comparação das respostas dos estudantes na primeira aplicação do questionário e depois da aplicação das demais atividades propostas, aplicando-se novamente as perguntas do primeiro momento, como veremos nos resultados.

\subsubsection{A aula de Cosmologia}

Através da aula expositiva mostramos os principais modelos cosmológicos: geocêntrico e heliocêntrico, com o objetivo de dar embasamento teórico sobre o tema. Começamos vendo o significado etimológico da palavra Cosmologia $(\mathrm{Cosmo}=$ mundo, lógica $=$ estudo $) . \mathrm{Em}$ seguida vimos os mitos da criação do Universo, de acordo com as versões da Bíblia, dos gregos, dos egípcios, e chinesa para finalmente estudarmos os modelos geocêntrico e heliocêntrico.

O modelo Geocêntrico passando por Platão e Aristóteles e aprimorado por Ptolomeu, quando atingiu seu ápice. No heliocentrismo vimos à revolução copernicana, tirando a Terra do centro do Universo, finalizando assim o estudo dos modelos cosmológicos de acordo com os estudos de Kepler e Galileu.

\subsubsection{Os Vídeos}

Os recursos tecnológicos são importantes apoio didático-pedagógico, pois, elas nos permitem realizar atividades de aprendizagem de forma diferenciadas das aulas tradicionais, apenas com aulas orais [3]. Assim, a utilização do vídeo Gravitação Universal - Modelos Cosmológicos (10 min e 40 seg) [7] e Movimentos de Rotação e translação da Terra (1 min e 22 seg) [8] proporcionaram um momento de melhor visualização dos fenômenos físicos envolvidos. No $1^{\circ}$ vídeo, por exemplo, são apresentados os dois modelos cosmológicos, com destaque para a história dos mesmos, enquanto que o vídeo Movimentos da Terra, nos mostra com bastante clareza os movimentos de translação e rotação da Terra. Essas atividades instigaram bastante os alunos, motivando-os para realização da atividade experimental.

\subsubsection{O Experimento}

O relógio de sol é um dispositivo muito antigo, que era utilizado para verificar as horas durante o dia. Segundo Pinto (2012) [4] este instrumento é: 
"Mais do que um objeto antigo, obsoleto do ponto de vista estritamente funcional, de valor decorativo variável e eventual interesse histórico - o seu valor científico é inestimável. Com efeito, áreas científicas muito diversas, como a Astronomia, a Trigonometria e a Geometria encontram no relógio de sol um campo fértil de investigação e aplicação de conhecimentos" (p. 9) [5].

A origem do relógio de sol é uma incerteza, acredita-se que os babilônios foram os primeiros a confeccionar. Com o desenvolvimento da trigonometria pelos matemáticos gregos, as marcações que indicavam as horas passaram a ser determinadas também aritmeticamente, permitindo o desenvolvimento dos mais sofisticados relógios de Sol [6]. Assim como um relógio possui ponteiros para a indicação das horas e uma engrenagem, o relógio de sol também possui ponteiro, porém a engrenagem neste caso é o próprio Sol.

Para confecção do relógio de Sol, utilizamos materiais de baixo custo: caixa de papelão de sapato branca, tesoura, caneta colorida, um transferidor, uma bússola e um palito de churrasco (Figura 5).

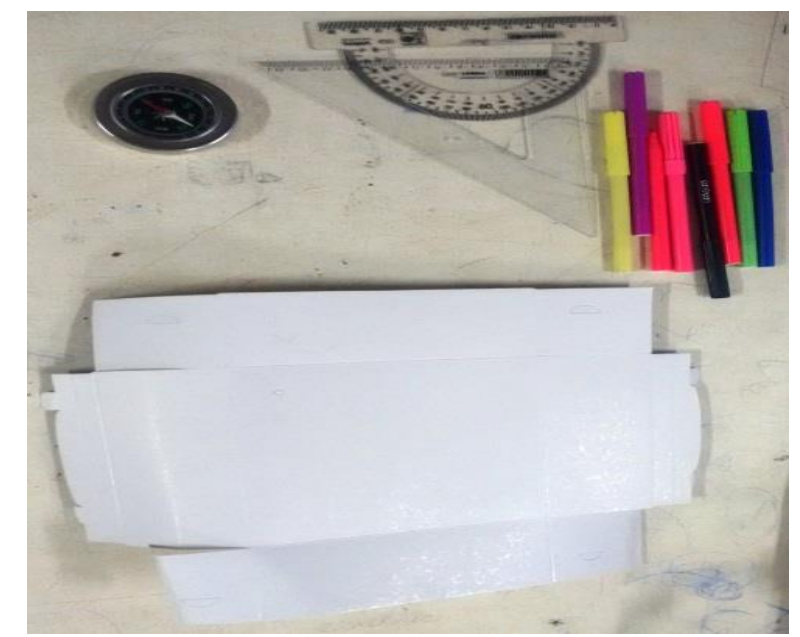

Figura 5: Material utilizado para confecção do relógio de Sol. Fonte:Os autores

Porém, antes da confecção do mesmo, primeiramente foi abordado em sala de aula como obter a inclinação correta do relógio de sol equatorial, por isto, o aluno deve garantir que o Gnômon (parte do relógio que faz a projeção da sombra) aponte para o polo celeste. Então, sua placa deve fazer um ângulo com a superfície horizontal igual à co-latitude $\left(90^{\circ}\right.$ - latitude do local) e como em Marabá/PA a Latitude é de $05^{\circ} 22^{\prime}$ 07' S, fazendo a diferença: $90-05=85^{\circ}$. Então o relógio deve ter a inclinação de $85^{\circ}$ em relação ao solo.

No dia da realização do experimento, os alunos compareceram e observamos o relógio de sol por volta das 17:00. Com o auxílio da bússola, colocamos o relógio direcionado ao norte magnético da terra e posteriormente, com a ajuda de uma "pedra" colocamos na inclinação correta, no caso $85^{\circ}$ (Figura 6).

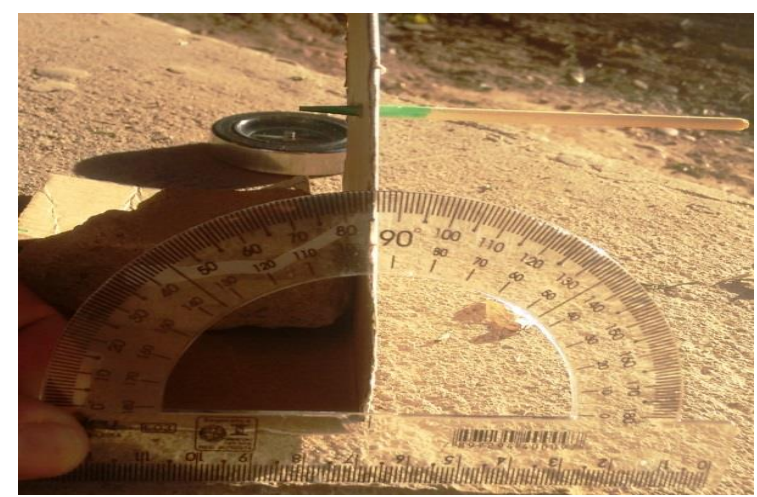

Figura 6: Inclinação do Relógio de Sol. Fonte: Os autores 
O experimento relógio de Sol fez o aluno lembrar-se do assunto abordado, pois através dele, o mesmo pôde associar o movimento aparente do sol, com o conteúdo ministrado em sala sobre os movimentos da Terra, além de ser um momento lúdico, de descontração e de compartilhamento do conhecimento fora da sala de aula. No horário de 17:00 h, conseguimos visualizar no relógio de Sol conforme se pode verificar na Figura 7.

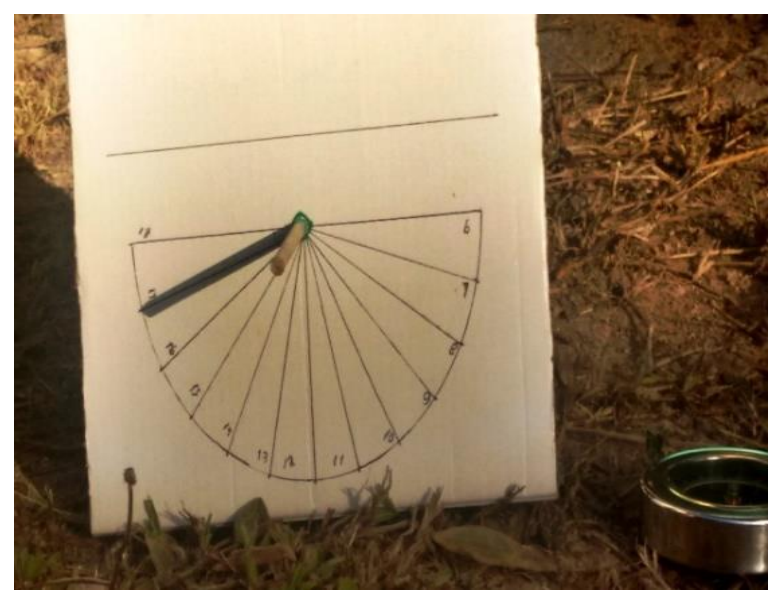

Figura 7: Visualização da hora no relógio de Sol. Fonte: Os autores

\title{
5. RESULTADOS E DISCUSSÃO
}

Neste trabalho, os questionários foram de fundamental importância na verificação do processo de ensino e aprendizagem. No momento inicial, obtivemos as seguintes categorias de respostas, conforme se pode observar na Figura 8.

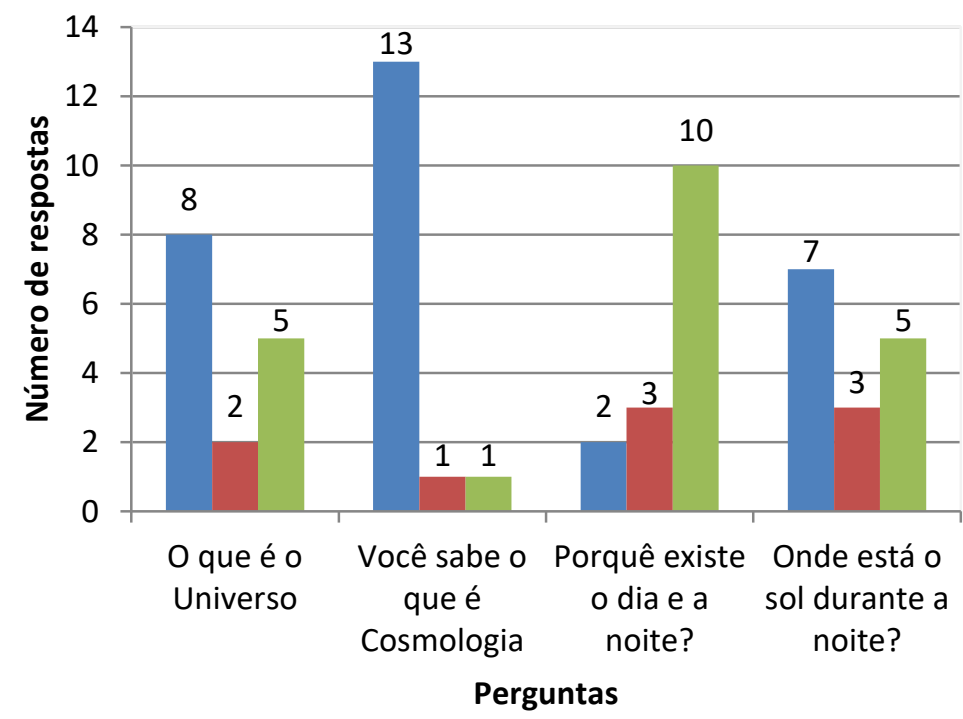

\author{
Não sabe \\ Respondeu corretamente \\ Não respondeu ou \\ respondeu errado
}

Figura 8: Número de respostas antes da aula.

Na Figura 8 pode-se constatar a falta de conhecimento dos alunos acerca do tema que foi proposto para estudo, pois a maioria não soube responder as questões em detrimento de uma minoria que respondeu corretamente. Um dado que chama atenção, é que apenas um aluno respondeu corretamente à questão 2 , sobre cosmologia, o que demonstra a falta de conhecimento ou informação por parte dos alunos sobre este assunto.

Após a aula de cosmologia, a apresentação dos vídeos e a realização do experimento relógio de sol, obteve-se os seguintes resultados sobre as mesmas questões aplicadas antes da realização de tais atividades, conforme apresentado na Figura 9. 


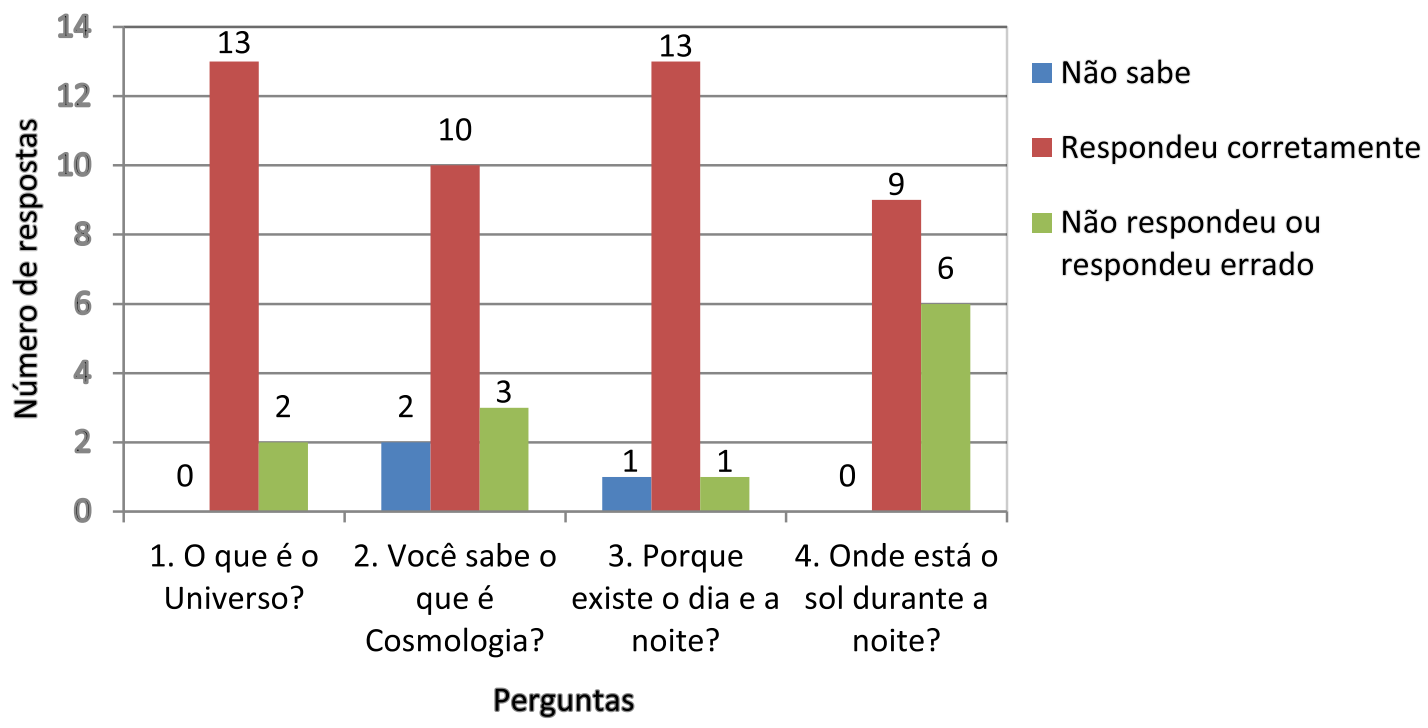

Figura 9: Número de respostas após a aula.

Os dados apresentados na Figura 9 revelam um aumento significativo na categoria "Respondeu corretamente", o que mostra claramente que a diversificação didático-pedagógica em aulas envolvendo recursos alternativos, experimentação e recursos tecnológicos, com ênfase na história, possibilitou aos alunos, em sua maioria, conseguirem responder o questionário de forma mais coerente, com respostas mais precisas sobre o assunto ministrado na aula.

A pesquisa evidenciou que ao incrementar uma motivação na aula, com auxílio de um vídeo documentário, história da Ciência, o uso de recurso didático manipulável e ainda construído pelos próprios alunos, proporcionou um maior rendimento na aprendizagem, e despertou o interesse pelo estudo dos modelos cosmológicos da Terra.

Ao aplicar a sequência didática embasada no CEK (Ciclo de Experiência Kellyana) foi verificada a efetividade do Corolário da individualidade onde cada aluno, por ser único, pôde expor suas ideias e conceitos relacionados ao tema estudado. Com relação ao Corolário da Construção, se observou que o aluno é construtor do seu próprio conhecimento e o mesmo cria suas réplicas para melhor compreensão dos modelos e das suas consequências, aqui aplicadas através da aula expositiva, da atenção dada aos vídeos e na construção do relógio de sol e, quanto ao Corolário da Experiência, verificou-se que o aluno é capaz de construir seu próprio conhecimento a partir da experiência vivenciada em sala de aula, bem como fora dela.

\section{CONCLUSÃO}

A partir das atividades desenvolvidas, incluído o questionário para sondar o conhecimento a respeito dos Modelos Cosmológicos da Terra foram alcançados expressivos resultados, demonstrando que os alunos absorveram melhor o conhecimento sobre o assunto. Destaca-se que o experimento com o relógio de Sol serviu como atividade prática de fixação do conteúdo em sala de aula e que se acredita tenha despertado o interesse dos alunos, principalmente em relação aos movimentos da Terra, aprendendo que na realidade quem gira é o nosso planeta, em torno de si mesma e ao redor do Sol, como verificado por Galileu Galilei há cerca de 400 anos atrás.

\section{REFERÊNCIAS BIBLIOGRÁFICAS}

1. Moreira MA. Teorias de Aprendizagem. São Paulo: EPU, 1999.

2. Azevedo MCPS. Ensino por investigação: problematizando as atividades em sala de aula. In: Carvalho AMP (Org.). Ensino de ciências: unindo a pesquisa e a prática. São Paulo: Pioneira T. Learning, 2004.

3. Moran J. Novas Tecnologias e Mediação Pedagógica. Física na Escola, Papirus, 21 a ed. p. 12-14 (com modificações). 2014. 
4. Pinto LFM. Funcionamento e traçado do relógio de sol. Rev Arquitectura Lusíada. 2012; 4:9-35.

5. Gerhardt TE, Silveira DT. Métodos de Pesquisa. Série Educação a Distância. UAB/UFRGS. Porto Alegre: Editora da UFRGS, 2009.

6. Moretto SS, Pessanha MCR, Schramm DUS, Souza MO. Relógio de Sol analêmico: uma proposta que envolve ensino, professor e aluno. In Anais do XIX Simpósio Nacional de Ensino de Física, Manaus, AM, 2011. [acesso em 25 jan 2019]. Disponível em: http://www.sbf1.sbfisica.org.br/eventos/snef/xix/sys/resumos/T0376-1.pdf.

7. Vídeo: Gravitação Universal. [Acesso em 16/05/2017]. Disponível em: https://www.youtube.com/watch?v=k0VmgQZ4sdk

8. Vídeo: Movimentos de Rotação e Translação. [Acesso em 16/05/2017], disponível em: https://www.youtube.com/watch?v=CiOezkc0_nA

9. Santos MTS et al. Uma aula de química seguindo a teoria dos modelos e o ciclo da experiência kellyana. Anais do II COINTER PDVL 2015. Formação de professores: práticas de ensino, avaliação e cooperação, no despertar para a carreira docente. Recife, 2015.

10. Brasil. Parâmetros Curriculares Nacionais/ Ensino Fundamental. Brasília: Ministério da Educação, 1999.

11. Infoescola: Navegando e aprendendo. Astronomia. [Acesso em 01/05/2019]. Disponível em: https://www.infoescola.com/astronomia.

12. Só Física. Gravitação Universal. Leis de Kepler. [Acesso em 01/05/2019]. Disponível em: https://www.sofisica.com.br/conteudos/Mecanica/GravitacaoUniversal/lk.php. 